\title{
Effects of Postoperative Methycobal Administration on Digital Replantation Based on Stellate Ganglion Stimulation
}

\author{
Yuewen Wang ${ }^{1}$, Ruilian $\mathrm{Ma}^{2, *}$ \\ ${ }^{1}$ Department of Orthopaedics, Affiliated Hospital of Inner Mongolia Medical University, Hohhot, China \\ ${ }^{2}$ Department of Pharmacy, Affiliated Hospital of Inner Mongolia Medical University, Hohhot, China
}

Email address:

nmgmrl@163.com (Ruilian Ma)

${ }^{*}$ Corresponding author

\section{To cite this article:}

Yuewen Wang, Ruilian Ma. Effects of Postoperative Methycobal Administration on Digital Replantation Based on Stellate Ganglion Stimulation. American Journal of Internal Medicine. Vol. 5, No. 4, 2017, pp. 67-69. doi: 10.11648/j.ajim.20170504.14

Received: May 25, 2017; Accepted: July 15, 2017; Published: August 2, 2017

\begin{abstract}
To study the impact of stellate ganglion block (SGB) on digital replantation and analyze its mechanism. Digital arterial diameter was enlarged after SGB, and the difference in the survival rate of severed finger after replantation was not statistically significant between the two groups $(\mathrm{P}>0.05)$. Through the treatment with Methycobal, the recovery of 2-point discrimination (2-pd) of the experimental groups (A, B) was significantly better than that of the negative control group, between which the difference was statistically significant $(\mathrm{P}<0.01$ between Groups A and $\mathrm{C}, \mathrm{P}<0.05$ between Groups $\mathrm{B}$ and $\mathrm{C})$, indicating that the methyl vitamin B 12 can significantly promote the regeneration of peripheral nerves. Methycobal is of great significance to the postoperative treatment of digital replantation, which is worthy of being widely applied in clinic practice.
\end{abstract}

Keywords: Stellate Ganglion, Digital Replantation, Methycobal, Treatment

\section{Introduction}

Vasospasm is a key factor that affects the survival rate of amputated finger after replantation. Currently, vasodilators have been limited to long-time application clinically for serious side effects [1]. This study observes that the therapy that stellate ganglion is stimulated by polarized infrared ray can alleviate the vasospasm of affected finger and improve its survival rate with few side effects [2]. Drug researches suggest that VitB 12 can promote the regeneration of peripheral nerves after injury, which is commonly used in the treatment of diabetic and drug-induced neuropathy [3, 4]. This study aims to explore the effect of nerve regeneration of Methycobal on peripheral nerves injury and compare the effect of Methycobal in different doses.

\section{Method}

\subsection{General Information}

A total of 70 patients who received digital replantation in Orthopedic Department of our hospital between June 2009 and June 2012 were involved in this study, all the injuries of whom were sharp instrument cuts. The patients included 46 males and 24 females. The injured parts were respectively located in thumb in 25 cases, index finger in 28 cases. All patients underwent debridement and digital replantation after admission.

\subsection{Stellate Ganglion Laser Irradiation}

\subsubsection{Grouping and Treatment Methods}

The patients with severed finger in the same position were randomly divided into treatment group $(n=30)$ and control group $(n=40)$, all of whom were required to quit smoking and lie in bed, and given the treatment of continuous light baking, anti-inflammation and anti-coagulation. The sternocleidomastoid, arteria carotis communis and vena jugularis interna were pressed to the outside to make the probe nearest to stellate ganglion.

\subsubsection{Observation and Relevant Indices}

PHILIPS HDI 5000 color Doppler ultrasound imaging system was adopted for the examination on amputated finger before and after SGB of proper digital artery. The supernatant was stored in low-temperature refrigerator at $-20^{\circ} \mathrm{C}$ for determination 


\subsection{Administration of Methycobal}

\subsubsection{Grouping and Treatment Methods}

Seventy patients after digital replantation were randomly divided into Groups A, B and C. Injection was given intramuscularly and tablet orally before meals. In Group A, $1000 \mu \mathrm{g}$ Methycobal was given intramuscularly once a day for twice and then $500 \mu \mathrm{g}$ orally 3 times a day for 3 months.

\subsubsection{Observation Indices and Evaluation Methods}

The patients received reexamination $1,5,9,13$ and 17 weeks after medication to determine the sensation of pressure at $30 \mathrm{~g}$, tactile sensation at $3 \mathrm{~g}$ and sensation of pain at $6 \mathrm{~g}$ and 2-pd respectively. The 2-pd variances in a group and between groups were analyzed with $\mathrm{F}$ test.

\subsection{Statistical Analysis}

The $t$ test was used for the comparison of indicators between groups, chi-square test for rate comparison. SPSS 13.0 statistical software was adopted, with all data expressed by (mean \pm standard deviation) $(\mathrm{x} \pm \mathrm{s}), \mathrm{P}<0.05$ for statistical significance.

\section{Results}

\subsection{Arterial Indices Before and After SGB}

Digital arterial diameter was thickened after SGB, the levels of VS, VD, TVA in digital artery increased, and RI decreased (Table 1). The difference in the survival rate after replantation was not statistically significant between the two groups (Table 2). In the treatment group, the contents of NPY and NE after SGB were statistically decreased compared with the control group (Table 3 and 4).

Table 1. Indices of arterial blood rheology before and after $S G B(x \pm s, n=30)$.

\begin{tabular}{lllll}
\hline Time & VS $(\mathbf{c m} / \mathbf{s})$ & VD $(\mathbf{c m} / \mathbf{s})$ & TVA $(\mathbf{c m} / \mathbf{s})$ & RI $(\mathbf{c m} / \mathbf{s})$ \\
\hline Before & $35.2 \pm 1.35$ & $17.5 \pm 1.50$ & $9.95 \pm 0.33$ & $0.60 \pm 0.12$ \\
After & $54.2 \pm 0.77 *$ & $23.6 \pm 1.51 *$ & $16.23 \pm 1.11 *$ & $0.24 \pm 0.13 *$ \\
\hline
\end{tabular}

*: Compared the results before treatment, $\mathrm{P}<0.05$.

Table 2. Survival rates of replanted fingers [case, (\%)].

\begin{tabular}{lllll}
\hline Group & Case No. & All & Partial & None \\
\hline Treatment group & 30 & $26(86.7)^{*}$ & $3(4.3)$ & $1(1.4)$ \\
Control group & 40 & $35(87.5)$ & $3(4.3)$ & $2(2.8)$ \\
\hline
\end{tabular}

*: Compared the results before treatment, $\mathrm{P}<0.05$.

Table 3. NPY at different time intervals ( $n g / L, x \pm s)$.

\begin{tabular}{|c|c|c|c|c|c|c|c|}
\hline \multirow{2}{*}{ Group } & \multirow{2}{*}{ Case No. } & \multirow{2}{*}{ Postoperative } & \multicolumn{5}{|c|}{ Postoperative } \\
\hline & & & $15 \mathrm{~min}$ & $1 \mathrm{~d}$ & $6 \mathrm{~d}$ & $12 \mathrm{~d}$ & $18 \mathrm{~d}$ \\
\hline Treatment group & 30 & $126.1 \pm 6.03$ & $99.0 \pm 3.02 *$ & $102.3 \pm 4.09 *$ & $103.5 \pm 8.14^{*}$ & $101.6 \pm 9.05^{*}$ & $109.4 \pm 8.03 *$ \\
\hline Control group & 40 & $127.3 \pm 6.03$ & $126.7 \pm 5.14$ & $124.2 \pm 6.13$ & $126.4 \pm 7.04$ & $127.2 \pm 8.11$ & $126.5 \pm 7.07$ \\
\hline
\end{tabular}

*: Compared with the control group, $\mathrm{P}<0.05$

Table 4. NE at different time intervals ( $n g / L, x \pm s)$.

\begin{tabular}{|c|c|c|c|c|c|c|c|}
\hline \multirow{2}{*}{ Group } & \multirow{2}{*}{ Case No. } & \multirow{2}{*}{ Postoperative } & \multicolumn{5}{|c|}{ Postoperative } \\
\hline & & & $15 \mathrm{~min}$ & $1 \mathrm{~d}$ & $6 \mathrm{~d}$ & $12 \mathrm{~d}$ & $18 \mathrm{~d}$ \\
\hline Treatment group & 30 & $3.93 \pm 1.65$ & $1.77 \pm 0.13 *$ & $1.91 \pm 0.53 *$ & $1.79 \pm 0.36 *$ & $1.88 \pm 0.08 *$ & $1.74 \pm 0.41 *$ \\
\hline Control group & 40 & $3.88 \pm 1.70$ & $3.90 \pm 1.53$ & $3.87 \pm 1.58$ & $3.95 \pm 1.61$ & $3.87 \pm 1.45$ & $3.96 \pm 1.66$ \\
\hline
\end{tabular}

*: Compared with the control group, $\mathrm{P}<0.05$.

\subsection{Follow-Up Outcomes of Methycobal Administration}

All patients were followed up for 3 to 6 months, with an average of 5.6 months. Patients were tested regularly in sensation of pressure at $30 \mathrm{~g}$, tactile sensation at $3 \mathrm{~g}$ and sensation of pain at $6 \mathrm{~g}$ and 2-pd. The results were shown in Table 5.

Table 5. Sensation of Group A during reexamination.

\begin{tabular}{|c|c|c|c|c|c|c|}
\hline \multirow{2}{*}{ Item } & \multirow{2}{*}{ Index } & \multicolumn{5}{|c|}{ Postoperative } \\
\hline & & 1st week & 5th week & 9th week & 13th week & 17th week \\
\hline Pressure (30 g) & 30 & 2 & $27(91.0 \%)$ & $30(99.9 \%)$ & $30(99.9 \%)$ & $30(99.9 \%)$ \\
\hline Tactile (3 g) & 30 & - & $16(53.2 \%)$ & $25(83.2 \%)$ & $30(99.9 \%)$ & $30(99.9 \%)$ \\
\hline Pain (6 g) & 30 & - & $11(36.6 \%)$ & $20(66.6 \%)$ & $30(99.9 \%)$ & $30(99.9 \%)$ \\
\hline $2-\mathrm{pd}<10 \mathrm{~mm}$ & 30 & - & - & $6(21.0 \%)$ & $22(73.2 \%)$ & $25(83.1 \%)$ \\
\hline
\end{tabular}

In the 17 th week, there were 5 fingers with 2 -pd $>10 \mathrm{~mm}$ (average: $12.5 \mathrm{~mm}$ ).

\section{Discussion}

Vascular crisis after digital replantation is one of the most important reasons for the necrosis of replanted finger [5]. Stellate ganglion is fused by the sixth and seventh cervical ganglion and the first thoracic ganglia, inhibiting neural excitability and nervous relaxation [6]. Polarized infrared ray has the characteristics of high energy density and deep transmission $[7,8]$, ease the oxygen balance disorder of the nervous system caused by sympathetic overactivity and reduce the reperfusion injury after tissue ischemia [9].

In the two groups of patients after the application of SGB, 
the diameter of artery was widened, and the arterial end-systolic and end-diastolic blood flow velocity and mean blood flow velocity increased. According to the formula $\mathrm{Re}=\mathrm{VDR} / \mathrm{G}$, the blood flow and mean arterial blood flow were proportional to vascular diameter [10]. It is found that NPY and NE, commonly located in sympathetic nerve endings, can cause intense contraction of small and medium-sized arteries, so as to induce and aggravate the reperfusion injury after tissue ischemia [11], the intracardiac contents of NPY and NE will be significantly reduced, or even disappear [12], and inhibits the cyclic stress response, thereby improving the capacity of the expansion of vascular bed, as well as the perfusion in marginal zone [13]. The recovery of sensory function requires not only quality nerve suture, but also the use of drugs on promoting nerve regeneration to accelerate neurological recovery [14]. The earlier the sensation occurs, the better the sensory function recovers [15]. Its mechanism of action is as follows: methyl VitB 12 can transfer into cell organelle of nerve cells flexibly, with a higher content in peripheral nerves, compared with ordinary VitB 12 [16]. The mechanism is mainly to enhance the nucleic acid and protein synthesis in nerve cells, and promote the synthesis of the main component of myelin sheath--lecithin $[17,18]$. The results of this study indicate that methyl VitB 12 can accelerate the growth of sensory nerve, promote the recovery of peripheral nerves injury, and this effect is positively correlated with the drug dose. Methyl VitB 12, with no apparent side effects, is worthy of a wide application in clinic.

\section{Acknowledgement}

This study was financially supported by the Nature Science Foundation of Inner Mongolia Autonomous Region (2017 MS 0831, for Ruilian Ma; http://nsbr.nmkjt.gov.cn/index.aspx).

\section{References}

[1] Chen YC, Chan FC, Hsu CC, Lin YT, Chen CT, Lin CH. Fingertip Replantation Without Venous Anastomosis. Ann Plast Surg. 2013; 70 (3): 284-8.

[2] Buckley T, Hammert WC. Anticoagulation following digital replantation. J Hand Surg Am. 2011; 36 (8): 1374-6.

[3] Franques J, Verschueren A. Metabolic neuropathies: Overview in 2011. Rev Neurol (Paris). 2012; 26 (12): 1002-8.

[4] Selhub J, Paul L. Folic acid fortification: why not vitamin B 12 also? Biofactors. 2011; 34 (7): 269-71.
[5] Barzin A, Hernandez-Boussard T, Lee GK, Curtin C. Adverse events following digital replantation in the elderly. J Hand Surg Am. 2011; 36 (5): 870-4.

[6] Zor F, Ozturk S, Usyilmaz S, Sengezer M. Is stellate ganglion blockade an option to prevent early arterial vasospasm after digital microsurgical procedures? Plast Reconstr Surg. 2006; 117 (3): 1059-60.

[7] Huang D, Gu YH, Liao Q, Yan XB, Zhu SH, Gao CQ. Effects of linear-polarized near-infrared light irradiation on chronic pain. Scientific World J. 2012; 2012: 567496.

[8] Diepgen TL, Drexler H, Schmitt J. Epidemiology of occupational skin cancer due to UV-irradiation. Hautarzt. 2012; 63 (10): 769-77.

[9] Nazerani S, Motamedi MH, Ebadi MR, Nazerani T, Bidarmaghz B. Experience with distal finger replantation: a 20 -year retrospective study from a major trauma center. Tech Hand Up Extrem Surg. 2011; 15 (3): 144-50.

[10] Zahedi E, Jaafar R, Ali MA, Mohamed AL, Maskon O. Finger photoplethysmogram pulse amplitude changes induced by flow-mediated dilation. Physiol Meas. 2008; 29 (5): 625-37.

[11] Keda T, Hirakawa H, Kemuriyama T, Nishida Y, Kazama T. Effect of cervical sympathetic trunk transection on renal sympathetic nerve activity in rats. Physiol Res. 2009; 58 (1): 77-82.

[12] Herzog H. 30 Years of NPY research. Neuropeptides. 2012; 46 (6): 251.

[13] Dönmez A, Tufan H, Tutar N, Araz C, Sezgin A, Karadeli E, Torgay A. In vivo and in vitro effects of stellate ganglion blockade on radial and internal mammary arteries. J Cardiothorac Vasc Anesth. 2005; 15 (6): 729-33.

[14] Mackinnon SE, Yee A, Ray WZ. Nerve transfers for the restoration of hand function after spinal cord injury. J Neurosurg. 2012; 117 (1): 176-85.

[15] Bíró V. Advances in reconstructive options of nerve injuries in the hand. Orv Hetil. 2012; 153 (45): 1767-78.

[16] Ting CS, Oldroyd JC, Levinson MR. Vitamin B 12 screening in older inpatients without known risk factors: why do clinicians measure it? Med J Aust. 2012; 197 (8): 442-3.

[17] Jansen EH, Beekhof PK, Cremers JW, Schenk E. Long-term (in)stability of folate and vitamin B 12 in human serum. Clin Chem Lab Med. 2012; 50 (10): 1761-3.

[18] Chemnitz A, Andersson G, Rosén B, Dahlin LB, Björkman A. Poor electroneurography but excellent hand function 31 years after nerve repair in childhood. Neuroreport. 2013; 24 (1): 6-9. 